\section{Epidermal Barrier: Negative Changes in Atopic Dermatitis and Positive Changes Induced by Short-term Suberythemal Ultraviolet B Irradiation}

\section{Felicia Permatasari, Bing-rong Zhou* and Dan Luo*}

Department of Dermatology, the First Affiliated Hospital of Nanjing Medical University, Nanjing, China

\begin{abstract}
Atopic Dermatitis (AD) is characterized clinically by chronic skin inflammation and intense pruritus, and pathologically by a defective skin barrier. We reviewed the main defects in $A D$ epidermal barrier and the positive effects of short-term suberythemal dose of Ultraviolet $B$ (UVB) on disrupted epidermal barrier. Although $A D$ has a correlation with Filaggrin (FLG) loss-of-function mutations, a study showed that the defective skin barrier is not inherent. Recent knowledge on the role of inflammation in inducing the disruption of skin barrier function has helped to understand $A D$ pathogenic mechanisms. It has been observed by many that $A D$ becomes more prevalent in winter, when people lack sufficient UVB for vitamin D synthesis. A study has demonstrated that a suberythemal dose of UVB exposure should suffice to generate synthesis of sufficient vitamin $D_{3}$ to impact downstream events in the epidermis. In conclusion, repeated short-term low doses of UVB irradiation on hairless mice significantly accelerate the kinetics of barrier recovery without clinically evident inflammation, one of the factors that disrupt the barrier function in $A D$. This might be a useful therapeutic strategy for the use of UVB irradiation for treating AD.
\end{abstract}

Keywords: Epidermal barrier; Atopic Dermatitis; Inflammation; Caspase 14; UVB; Suberythemal dose; Vitamin D

*Corresponding author: Bing-rong Zhou, Department of Dermatology, the First Affiliated Hospital of Nanjing Medical University, Nanjing, China, 21002, Tel: +86-25-8679-6545; E-mail: bingrong.2002@163.com

Dan Luo, Department of Dermatology, the First Affiliated Hospital of Nanjing Medical University, Nanjing, China, 21002, Tel: +86-25-8679-6545; E-mail: daniluo2013@njmu.edu.cn

Citation: Permatasari F, Zhou B, Luo D (2014) Epidermal Barrier: Negative Changes in Atopic Dermatitis and Positive Changes Induced by Short-term Suberythemal Ultraviolet B Irradiation. J Clin Dermatol Ther 1: 001.

Received: April 20, 2014; Accepted: June 07, 2014; Published: June 23, 2014

\author{
Abbreviations \\ AD: Atopic Dermatitis \\ UVB: Ultraviolet B \\ FLG: Filaggrin \\ SC: Stratum Corneum \\ CER: Ceramides \\ LB: Lamellar Bodies \\ $\beta$-GlcCerase: B-Glucocerebrosidase \\ AMP: Antimicrobial Peptides \\ SPT: Serine Palmitoyltransferase \\ SCCE: Stratum Corneum Chymotryptic Enzyme \\ TEWL: Transepidermal Water Loss \\ NMF: Natural Moisturizing Factors \\ FAS: Fatty Acid Synthase

\section{Introduction}

Atopic Dermatitis (AD) is characterized clinically by chronic skin inflammation and intense pruritus, and pathologically by a defective skin barrier. It has been observed by many that $\mathrm{AD}$ becomes more prevalent in winter, when people lack sufficient Ultraviolet B (UVB) for vitamin D synthesis [1]. Thus, UVB radiation has been applied for the treatment of $\mathrm{AD}$ [2-4]. However, UVB irradiation on the skin is known to induce disruption of the epidermal barrier [5,6], and AD is characterized by a defective skin barrier [7]. Moreover, long-term and/or high dose of UVB irradiation can damage the barrier function [6].

We reviewed the negative changes of epidermal barrier in $\mathrm{AD}$ and the positive changes caused by short-term low doses of UVB irradiation in the epidermal barrier, with the aim of understanding the possible therapeutic strategy on using UVB irradiation for treating AD.

\section{Negative Changes of Epidermal Barrier in Atopic Dermatitis}

Although $\mathrm{AD}$ has a correlation with Filaggrin (FLG) loss-of-function mutations, a study showed that the defective skin barrier is not inherent [8]. Another study showed that there is a reduced skin barrier in $\mathrm{AD}$ patients, irrespective of FLG genotype, implying that other factors besides FLG loss-of-function mutations modulate skin barrier integrity [9]. Various causes for the impaired barrier in $\mathrm{AD}$ have been suggested, mainly are the changes in the epidermal barrier, the disrupted Stratum Corneum (SC) [10].

\section{Decreased CER, decreased covalently bound CER, decreased involucrin}

The lipids that constitute the extracellular matrix are $15 \%$ fatty acids, $25 \%$ cholesterol, and 50\% Ceramides (CER) [11]. The relative quantities of these three key lipids are important for the formation of Lamellar Bodies (LB). An excess or deficiency of a particular lipid can disturb LB formation [12]. Therefore the relative quantities of the three lipids are important for maintaining barrier homeostasis.

There is a decrease in total SC lipids in AD skin [13]. A disturbance of maturation and extrusion of LB has been demonstrated, consisting 
of a decreased release of the acid, lipid, and enzyme constituents of the SC, resulting in decreased lipid contents of the SC $[14,15]$. In dry atopic skin, SC lipid is abnormal with elevated level of cholesterol and free fatty acids, and reduction in the amount of phospholipids and CER $[16,17]$. The decreased CER may be caused by reduced activation of $\beta$-Glucocerebrosidase ( $\beta$-GlcCerase), sphingomyelinase, and reduced prosaposin levels in $\mathrm{AD}$ [18]. In addition, the highly upregulated sphingomyelin deacyclase may also cause a CER deficiency as a result of competition with $\beta$-GlcCerase and sphingomyelinase for their respective substrates, sphingomyelin and glucosylceramide [19]. Downregulation of the de novo synthesis of CER in AD [20], possibly due to the decreased expression of Serine Palmitoyltransferase (SPT) [21], may also account for the decreased CER in AD. There is also a reduced amount of $\omega$-hydroxyceramide bound to the cornified envelope, also called covalently bound CER, possibly due to the reduced expression of involucrin in $\mathrm{AD}[18,20]$.

\section{Decreased average CER chain length}

The average CER chain length was significantly decreased in $\mathrm{AD}$ patients $(p=0.012)$. No difference was observed between carriers and noncarriers of FLG mutations. In nonlesional skin of AD patients, extremely short C34 CERs were increased within several CER subclasses. This was primarily observed in CER subclasses [AS], [AH], $[\mathrm{NS}]$, and $[\mathrm{NH}]$. The increase in total C34 CERs in $\mathrm{AD}(\mathrm{p}<0.0001)$ contributes to a reduction in overall chain length. In addition, the very long chain CERs belonging to the [EO] subclass are significantly reduced, which is primarily caused by significantly decreased levels of CER [EOH] and [EOP] ( $\mathrm{p}=0.019$ and $\mathrm{p}=0.040$, respectively). The influence of FLG mutations on any of the CER chain length parameters was not significant $(\mathrm{p}>0.1)$ [22].

CER [EOH] and CER [AS] are the two subclasses that are most significantly associated with TEWL. This again indicates the importance of the chain length for the skin barrier in $\mathrm{AD}$ : the exceptionally long CER [EOH] is decreased, whereas CER [AS], the CER subclass with the highest abundance of exceptionally short C34 CERs, is increased.

Changes in CER [EO] and C34 CER levels affect the lamellar organization. When focusing on the lateral organization, $\mathrm{AD}$ patients show a less dense lipid packing compared with controls that correlates strongly with a higher level of C34 CERs. This finding shows that CER chain length is also an important determinant of the lateral lipid organization in SC. The observed changes in lamellar and lateral organization correlate with the increased TEWL levels and thus with an abnormal skin barrier function in patients with $\mathrm{AD}$ [22].

Changes in lipids correlated with NMF levels but not with the presence or absence of FLG mutations. This suggests that between FLG gene (genotype) and NMF (phenotype), other (translational and environmental) factors may also influence NMF levels. Thus, despite the fact that we did not find a correlation between the lipids and FLG mutation status, FLG might play an indirect role in the decreased barrier function of $\mathrm{AD}$ patients, although the underlying mechanism remains unclear [22].

The findings in this study strongly support the hypothesis that, in $\mathrm{AD}$ patients, a reduction in CER chain length leads to a change in lipid organization, which in turn leads to an impaired barrier function. In addition, the impaired barrier function is correlated with disease severity as determined by SCORAD. This may indicate that, as a result of inflammation, lipid synthesis is influenced (even at nonlesional sites), and subsequently, the barrier function is decreased [22].

\section{Decreased antimicrobial peptide expression}

Antimicrobial Peptides (AMP) are only negligibly present in normal skin, but accumulate in skin affected by inflammatory diseases such as psoriasis. Certain AMP is essential for the homeostasis of the permeability barrier [23]. It has been shown that there is no increase in some AMP mRNA in AD compared to normal skin, in contrast to psoriasis [24]. There may be an intrinsic lack of activation of AMP in $\mathrm{AD}[18]$.

\section{Increased $\mathrm{pH}$, increased serine proteases activity}

The structural integrity of the Stratum Corneum is maintained by the presence of modified desmosomes, called corneodesmosomes. Corneodesmosomes lock the corneocytes together and provide tensile strength for the Stratum Corneum to resist shearing forces [25]. Cleavage of all peripheral corneodesmosomes at the skin surface must be completed for normal desquamation to occur [26,27]. Proteases break down the extracellular corneodesmosomal adhesion proteins that bind the corneocytes together and in doing so allow the corneocytes to shed from the skin surface [28].

These proteases, like many enzymes involved in skin barrier homeostasis and restoration, have been shown to be $\mathrm{pH}$ dependent [29]. The skin protease Stratum Corneum Chymotryptic Enzyme (SCCE), which also takes part in desquamation process, exhibits a neutral $\mathrm{pH}$ optimum [30]. A change in $\mathrm{pH}$ from 7.5 to 5.5 reduces SCCE activity by $50 \%[28,30]$. In patients with $\mathrm{AD}$, skin $\mathrm{pH}$ was reported to be 0.5 units higher than in control subjects [31]. The higher $\mathrm{pH}$ may increase the activity of proteases in $\mathrm{AD}$, leading to abnormal desquamation and thinning of the SC, thus disrupted the epidermal barrier. The increased activity of serine proteases may also lead to inflammation through cytokine activation [32]. The higher $\mathrm{pH}$ in $\mathrm{AD}$ may also affect the activity of enzymes in the lamellar lipid matrix of the SC involved in CER synthesis and epidermal differentiation, such as $\beta$-GlcCerase and sphingomyelinase [33], which may also account for the decreased CER in SC.

\section{Decreased SC hydration}

Increased Transepidermal Water Loss (TEWL) and reduced SC water content in $\mathrm{AD}$ reflects the diminished hydration leading to dry skin, which is the cardinal symptom of AD. Decreased SC hydration alone suffices to stimulate epidermal hyperplasia and early evidence of inflammation [32]. A study demonstrated that the impaired function of the SC only occurred after the observed infants developed AD. These changes were not observed soon after birth (from 4 to 12 days) when the skin surface showed only xerotic changes regardless of the later development of AD or atopic family background [34,35]. This showed that the impairments of SC functions found in $\mathrm{AD}$ patients result from the inflammation of the skin, which is thought to be present in the atopic dry skin [8].

\section{Inflammation induced-Caspase 14 downregulation}

FLG is essential to an intact skin barrier and hydration of the epidermis [36-38]. The breakdown of FLG, a process mediated among others by caspase 14, leads to liberation of hygroscopic amino acids that act as Natural Moisturizing Factors (NMF), which are very important for water binding of the SC [39-42]. Skin biopsies from $\mathrm{AD}$ patients have shown diminished expression of caspase 14 in the stratum granulosum [43]. Yet diminished caspase 14 expression has also been the case in biopsies from contact dermatitis and psoriasis [44]. An inflammation-induced downregulation of caspase 14 with 
subsequent loss of NMF may affect the barrier function of AD skin, regardless of FLG mutations.

\section{Can Atopic Dermatitis be Completely Healed?}

Several studies have reported that patients with $\mathrm{AD}$ have a defective skin barrier that even exists in nonlesional skin as characterized by increased TEWL [7,45]. However, a study has demonstrated that the difference in the increased TEWL and reduced SC water content in patients with completely healed AD compared to normal control is not significant [46]. Thus, the barrier function recovers to normal levels when the $\mathrm{AD}$ has completely healed $[46,47]$, suggesting that the disrupted barrier function in $\mathrm{AD}$ can be treated and maintained at normal condition.

\section{The Relationship of AD, Vitamin D, and UVB}

In intertropical zones (between latitudes $23.5^{\circ} \mathrm{N}$ and $23.5^{\circ} \mathrm{S}$ ), UVB rays are more intense and vitamin $\mathrm{D}$ synthesis is possible throughout the year [1]. In temperate zones $\left(23.5^{\circ}-66.5^{\circ}\right)$, people lack sufficient UVB for vitamin D synthesis for 1 month during the year, while those closer to the poles do not get enough UVB radiation for most of the year $[1,48-50]$. It is also influenced by the season of the year, with a seasonal decline occurring in winter $[1,51]$, the same season of the year when Atopic Dermatitis (AD) becomes worse or more prevalent.

A study by Vahavihu et al. demonstrated that 17 patients (94\%) with $\mathrm{AD}$ had vitamin $\mathrm{D}$ insufficiency (calcidiol $<50 \mathrm{nmol} / \mathrm{L}$ ), and 7 patients among them had vitamin D deficiency (calcidiol $<25 \mathrm{nmol} / \mathrm{L}$ ) [52]. A study by Peroni et al. [53] has demonstrated that the serum levels of $25(\mathrm{OH}) \mathrm{D}$ were higher in children with mild $\mathrm{AD}$ compared to those with moderate or severe cases $(\mathrm{p}<0.05)$ [53]. These results suggest that vitamin $\mathrm{D}$ deficiency may be related to the severity of $\mathrm{AD}$.

Byremo et al. [54] conducted a study in which 30 randomly selected children from 4-13 years of age with severe $\mathrm{AD}$ in Norway (subarctic/temperate climate) moved into a tropical zone for 4 weeks and the other 26 children remained in Norway, then were followed up for 3 months. A significant reduction in clinical signs and symptoms, an improvement in the quality of life index, and reduced use of topical corticosteroids was observed in the children that moved into a tropical zone after 4 weeks and 3 months $(\mathrm{p}<0.0005)$ [54]. The study results suggest that enough doses of UVB radiation to generate sufficient vitamin $\mathrm{D}$ synthesis have the potential to treat $\mathrm{AD}$.

\section{Positive Changes of Epidermal Barrier Induced by Short-term Low Doses of UVB Irradiation}

Both natural and artificial UVB irradiations are commonly used in the treatment of $\mathrm{AD}[3,4]$. The same dose of UVB exposure gives different effects on different skin types. The Minimal Erythema Dose (MED) of a fair-skinned (Fitzpatrick type I) person is approximately 10 to $25 \mathrm{~mJ} / \mathrm{cm}^{2}[55,56]$. Those with darker skin needs higher level of MED to produce the same effect [57]. Therefore, in the UVB treatment, the skin type of the patients also determines the treatment dose. Exposure dose is an important factor in determining the effects of UVB exposure since UV-induced DNA damage and barrier disruption increase linearly with increasing dose $[6,58]$.

A study on hairless mice exposed to 0.5 MED of UVB irradiation $\left(40 \mathrm{~mJ} / \mathrm{cm}^{2}\right)$ daily for 3 days demonstrated positive effects of UVB on epidermis, which, at least in part, is mediated by cutaneous vitamin $\mathrm{D}_{3}$ activation [59]. There was an upregulation of cutaneous vitamin $\mathrm{D}_{3}$ system and an increase in the mRNA levels for the epidermal lipid synthetic enzymes, HMG-CoA, Fatty Acid Synthase (FAS), and SPT [59]. There was also an upregulation of AMP in the outer epidermis, which is thought to be mediated through cutaneous production of $1,25(\mathrm{OH})_{2} \mathrm{D}_{3}$, the most active form of vitamin $\mathrm{D}_{3}$. There was also an increase in the expression of involucrin and FLG, without the concurrent development of epidermal hyperplasia, implying that UVB can also regulate the epidermal differentiation [59]. Moreover, there was no clinically evident inflammation or barrier disruption [59]. Another study using 0.5 MED of UVB irradiation for 3 days prior to tape-stripping showed significantly accelerated barrier recovery rates $[6,59]$.

According to a study by Janssens et al., decreased CER [EOH] level and increased CER [AS] level in AD patients are most significantly associated with TEWL [22]. Therefore, to increase the level of CER $[\mathrm{EOH}]$ and to decrease the level of CER [AS] might be a novel therapeutic entry to repair skin barrier defects in $\mathrm{AD}$ patients. A study by Jakob Mutanu Jungersted et al. demonstrated that after 18 treatments of UV light therapy (UVB, UVA, and psoralen+UVA), $\mathrm{CER}[\mathrm{EOH}]$ was increased and CER $[\mathrm{AS}+\mathrm{AH}]$ were decreased. The dosage and period of UV light therapy were not mentioned [60]. A study by Yutaka Takagi et al. demonstrated that a single UVB irradiation at a dose of $75 \mathrm{~mJ} / \mathrm{cm}^{2}$ impaired the skin barrier. The results showed increased level of CER [EOH] and CER [AS] simultaneously. However, a closer look at the result showed that the ratio of CER [EOH] to CER [AS] was slightly increased after UVB irradiation. This shows an interesting potential of UVB irradiation on improving the average Cer chain length, even at a dose known to disrupt the skin barrier [21]. Further studies to investigate the effectiveness of short-term suberythemal UVB on average CER chain length in $\mathrm{AD}$ patients are required.

$1,25(\mathrm{OH}) \mathrm{D}$ has been demonstrated to increase expression of major epidermal differentiation proteins, such as involucrin, loricrin, FLG, and transglutaminase, as well as to stimulate cornified envelope formation [59]. In vitro studies show that $1,25(\mathrm{OH}) \mathrm{D}$ induces the expression of cathelicidin-a broad spectrum AMP-in keratinocytes [61]. Exposure to UVB radiation in sunlight is the most efficient way to boost vitamin D supply but it is still unclear how much sunlight is required to produce a given level of $25(\mathrm{OH}) \mathrm{D}$. Environmental and personal factors greatly affect vitamin $\mathrm{D}$ production in the skin, making it impossible to recommend a one-size-fits-all level of exposure for the general population. It has been consistently shown that vitamin $\mathrm{D}$ can be efficiently and sufficiently produced at doses of UVB below those which cause reddening of the skin or sunburn $[62,63]$. A suberythemal dose of UVB exposure should suffice to generate synthesis of sufficient vitamin $\mathrm{D}_{3}$ to impact downstream events in the epidermis leading to barrier recovery $[6,59]$.

\section{Short-term Suberythemal UVB and Vitamin D Supplementation}

Amestejani et al. [64] conducted a study in which $30 \mathrm{AD}$ patients received vitamin $\mathrm{D} 1,600 \mathrm{IU} /$ day and the other $30 \mathrm{AD}$ patients received placebo. After 60 days, the group treated with vitamin $\mathrm{D}$ improved significantly, regardless of the initial severity of $\mathrm{AD}(\mathrm{p}<0.05)$, whilst the improvement in the placebo group was not significant $(\mathrm{p}>0.05)$ [64]. A study by Byremo et al. [54] demonstrated that 30 randomly selected children from 4-13 years of age with severe AD in Norway (subarctic/temperate climate) were significantly improved after they were moved into a tropical zone for 28 days. The study results show 
Citation: Permatasari F, Zhou B, Luo D (2014) Epidermal Barrier: Negative Changes in Atopic Dermatitis and Positive Changes Induced by Short-term Suberythemal Ultraviolet B Irradiation. J Clin Dermatol Ther 1: 001.

that the effect of vitamin D supplementation will be significant after 60 days of daily vitamin $\mathrm{D}$ intake, whilst the effect of natural exposures (no known average doses of UVB exposure) of $\mathrm{AD}$ patients to sunlight (UVB radiation) will be significant after 28 days.

The present literature evidences show that a short-term suberythemal UVB therapy may benefit AD patients by yielding several advantages: a relatively quick treatment outcome, a direct effect on the epidermal barrier since UVB exposures can be directed only onto the lesional $\mathrm{AD}$ skin, the treatments are done with controlled unharmful UVB doses by experts in this field, and less responsibility especially for children to take daily vitamin $\mathrm{D}_{3}$ supplementation. A study comparing the effects and costs of vitamin $\mathrm{D}$ supplementation with a short-time suberythemal UVB course in the treatment of $A D$ would be of importance.

\section{Conclusion}

The defective skin barrier in $\mathrm{AD}$ is not inherent. Inflammation-induced downregulation of caspase 14 and decreased average CER chain length with subsequent loss of NMF may be responsible for disrupting the barrier function of $\mathrm{AD}$ skin, regardless of FLG mutations. Therefore, AD can be healed and maintained at normal condition. Repeated, short-term exposures to low-dose UVB on hairless mice significantly accelerate the kinetics of barrier recovery without clinically evident inflammation. Since inflammation is one of the factors that may disrupt the barrier function in $\mathrm{AD}$, using UVB irradiation while attempting to avoid further barrier disruption and/or inflammation might be a useful therapeutic strategy for the use of UVB irradiation for treating AD. Further studies are needed to determine the efficacy of the repeated short-term exposures to low dose UVB irradiation on the skin of patients with AD.

\section{Acknowledgments}

This work was supported by Grants from the China National Natural Science Foundation (81000700, 81171518, and 81301384), science project from Traditional Chinese Medicine Bureau of Jiangsu Province (LZ11084), Jiangsu National Natural Science Foundation (BK2012877), and the Priority Academic Program Development (PAPD) of Jiangsu Higher Education Institutions.

\section{Reference}

1. Mesquita Kde C, Igreja AC, Costa IM (2013) Atopic dermatitis and vitamin D: facts and controversies. An Bras Dermatol 88: 945-953.

2. Valkova S, Velkova A (2004) UVA/UVB phototherapy for atopic dermatitis revisited. J Dermatolog Treat 15: 239-244.

3. Jekler J, Larko O (1988) UVB phototherapy of atopic dermatitis. Br J Dermatol 119: 697-705

4. Wulf HC, Bech-Thomsen N (1998) A UVB phototherapy protocol with very low dose increments as a treatment of atopic dermatitis. Photodermatol Photoimmunol Photomed 14: 1-6.

5. Haratake A, Uchida Y, Schmuth M, Tanno O, Yasuda R, et al. (1997) UVB-induced alterations in permeability barrier function: roles for epidermal hyperproliferation and thymocyte-mediated response. J Invest Dermatol 108:769775

6. Permatasari F, Zhou B, Luo D (2013) Epidermal barrier: Adverse and beneficial changes induced by ultraviolet $B$ irradiation depending on the exposure dose and time (Review). Exp Ther Med 6: 287-292.

7. Hata M, Tokura Y, Takigawa M, Sato M, Shioya Y, et al. (2002) Assessment of epidermal barrier function by photoacoustic spectrometry in relation to its importance in the pathogenesis of atopic dermatitis. Lab Invest 82:14511461
8. Saijo S, Tagami H (1991) Dry skin of newborn infants: functional analysis of the stratum corneum. Pediatr Dermatol 8:155-159.

9. Jakasa I, Koster ES, Calkoen F, McLean WH, Campbell LE, et al. (2011) Skin barrier function in healthy subjects and patients with atopic dermatitis in relation to filaggrin loss-of-function mutations, J Invest Dermatol. 131: 540-542.

10. Proksch E, Brandner JM, Jensen JM (2008) The skin: an indispensable barrier. Exp Dermatol 17: 1063-1072.

11. Elias PM, Feingold KR (2006) Skin barrier, Taylor \& Francis, New York.

12. Feingold KR (2007) Thematic review series: skin lipids. The role of epidermal lipids in cutaneous permeability barrier homeostasis. J Lipid Res 48: 25312546.

13. Jakobza D, Reichmann G, Langnick W, Langnick A, Schulze P (1981) Surface skin lipids in atopic dermatitis. Dermatol Monatsschr 167: 26-29.

14. Elias PM, Schmuth M (2009) Abnormal skin barrier in the etiopathogenesis of atopic dermatitis. Curr Allergy Asthma Rep 9: 265-272.

15. Fartasch M, Diepgen TL (1992) The barrier function in atopic dry skin. Disturbance of membrane-coating granule exocytosis and formation of epidermal lipids? Acta Derm Venereol Suppl (Stockh) 176: 26-31.

16. Imokawa G, Abe A, Jin K, Higaki Y, Kawashima M, et al. (1991) Decreased level of ceramides in stratum corneum of atopic dermatitis: an etiologic factor in atopic dry skin? J Invest Dermatol 96: 523-526.

17. Di Nardo A, Wertz P, Giannetti A, Seidenari S (1998) Ceramide and cholesterol composition of the skin of patients with atopic dermatitis. Acta Derm Venereol 78: 27-30

18. Proksch E, Folster-Holst R, Jensen JM (2006) Skin barrier function, epidermal proliferation and differentiation in eczema. J Dermatol Sci 43: 159-169.

19. Hara J, Higuchi K, Okamoto R, Kawashima M, Imokawa G (2000) High-expression of sphingomyelin deacylase is an important determinant of ceramide deficiency leading to barrier disruption in atopic dermatitis. J Invest Dermatol 115: 406-413.

20. Macheleidt O, Kaiser HW, Sandhoff K (2002) Deficiency of epidermal protein-bound omega-hydroxyceramides in atopic dermatitis. J Invest Dermatol 119:166-173.

21. Takagi Y, Nakagawa H, Kondo H, Takema Y, Imokawa G (2004) Decreased levels of covalently bound ceramide are associated with ultraviolet $B$-induced perturbation of the skin barrier. J Invest Dermatol 123:1102-1109.

22. Aberg KM, Man MQ, Gallo RL, Ganz T, Crumrine D, et al. (2008) Co-regulation and interdependence of the mammalian epidermal permeability and antimicrobial barriers. J Invest Dermatol 128: 917-925.

23. Ong PY, Ohtake T, Brandt C, Strickland I, Boguniewicz M, et al. (2002) Endogenous antimicrobial peptides and skin infections in atopic dermatitis. $\mathrm{N}$ Engl J Med 347: 1151-1160.

24. Serre G, Mils V, Haftek M, Vincent C, Croute F, et al. (1991) Identification of late differentiation antigens of human cornified epithelia, expressed in re-organized desmosomes and bound to cross-linked envelope. J Invest Dermatol 97: 1061-1072.

25. Lundstrom A, Egelrud T (1988) Cell shedding from human plantar skin in vitro: evidence of its dependence on endogenous proteolysis. J Invest Dermatol 91: 340-343.

26. Egelrud T, Lundstrom A (1990) The dependence of detergent-induced cell dissociation in non-palmo-plantar stratum corneum on endogenous proteolysis. J Invest Dermatol 95: 456-459.

27. Caubet C, Jonca N, Brattsand M, Guerrin M, Bernard D, et al. (2004) Degradation of corneodesmosome proteins by two serine proteases of the kallikrein family, SCTE/KLK5/hK5 and SCCE/KLK7/hK7. J Invest Dermatol 122:12351244.

28. Schmuth M, Man MQ, Weber F, Gao W, Feingold KR (2000) Permeability barrier disorder in Niemann-Pick disease: sphingomyelin-ceramide processing required for normal barrier homeostasis. J Invest Dermatol 115: 459-466. 
Citation: Permatasari F, Zhou B, Luo D (2014) Epidermal Barrier: Negative Changes in Atopic Dermatitis and Positive Changes Induced by Short-term Suberythemal Ultraviolet B Irradiation. J Clin Dermatol Ther 1: 001

29. Ekholm IE, Brattsand M, Egelrud T (2000) Stratum corneum tryptic enzyme in normal epidermis: a missing link in the desquamation process? J Invest Dermatol 114: 56-63

30. Locker G (1961) Permeabilita"tspru" fung der Haut Ekzemkranker und Hautgesunder fu" $r$ den neun Indikator Nitrazingelh "Geigy," Modifizierung der alkaliresistenzprobe, $\mathrm{pH}$-verlauf in der Tiefe des stratum corneum. Dermatologica 124: 159-182.

31. Elias PM, Schmuth M (2009) Abnormal skin barrier in the etiopathogenesis of atopic dermatitis. Curr Opin Allergy Clin Immunol 9: 437-446.

32. Jensen JM, Folster-Holst R, Baranowsky A, Schunck M, Winoto-Morbach S et al. (2004) Impaired sphingomyelinase activity and epidermal differentiation in atopic dermatitis. J Invest Dermatol 122 1423-1431.

33. Fartasch M, Bassukas ID, Diepgen TL (1992) Disturbed extruding mechanism of lamellar bodies in dry non-eczematous skin of atopics. $\mathrm{Br} \mathrm{J}$ Dermato 127: 221-227.

34. Kikuchi K, Kobayashi H, O'Goshi K, Tagami H (2006) Impairment of skin barrier function is not inherent in atopic dermatitis patients: a prospective study conducted in newborns. Pediatr Dermatol 23: 109-113.

35. Ginger RS, Blachford S, Rowland J, Rowson M, Harding CR (2005) Filaggrin repeat number polymorphism is associated with a dry skin phenotype. Arch Dermatol Res 297: 235-241.

36. Sergeant A, Campbell LE, Hull PR, Porter M, Palmer CN, et al. (2009) Heterozygous null alleles in filaggrin contribute to clinical dry skin in young adults and the elderly. J Invest Dermatol 129: 1042-1045

37. Kezic S, Kemperman PM, Koster ES, De Jongh CM, Thio HB, et al. (2008) Loss-of-function mutations in the filaggrin gene lead to reduced level of natural moisturizing factor in the stratum corneum. J Invest Dermatol 128: 2117 2119

38. Denecker G, Ovaere P, Vandenabeele P, Declercq W (2008) Caspase-14 reveals its secrets. J Cell Biol 180: 451-458.

39. Scott IR, Harding CR (1986) Filaggrin breakdown to water binding compounds during development of the rat stratum corneum is controlled by the water activity of the environment. Dev Biol 115: 84-92.

40. Denecker G, Hoste E, Gilbert B, Hochepied T, Ovaere P, et al. (2007) Caspase-14 protects against epidermal UVB photodamage and water loss. Nat Cell Biol 9: 666-674.

41. Nicotera P, Melino G (2007) Caspase-14 and epidermis maturation. Nat Cell Biol 9: 621-622.

42. Vestergaard C, Hvid M, Johansen C, Kemp K, Deleuran B, et al. (2012) Inflammation-induced alterations in the skin barrier function: implications in atopic dermatitis. Chem Immunol Allergy 96: 77-80.

43. Hvid M, Johansen C, Deleuran B, Kemp K, Deleuran M, et al. (2011) Regulation of caspase 14 expression in keratinocytes by inflammatory cytokines--a possible link between reduced skin barrier function and inflammation? Exp Dermatol 20: 633-636.

44. Janssens M, van Smeden J, Gooris GS, Bras W, Portale G, et al. (2012) Increase in short-chain ceramides correlates with an altered lipid organization and decreased barrier function in atopic eczema patients. J Lipid Res 53: 2755-2766.

45. Leung DY, Boguniewicz M, Howell MD, Nomura I, Hamid QA (2004) New insights into atopic dermatitis. J Clin Invest 113: 651-657.

46. Matsumoto $M$, Sugiura $H$, Uehara $M$ (2000) Skin barrier function in patients with completely healed atopic dermatitis. J Dermatol Sci 23: 178-182.
47. Loffler H, Effendy I (1999) Skin susceptibility of atopic individuals. Contact Dermatitis 40: 239-242.

48. Arabi A, Rassi R, El-Hajj Fuleihan G (2010) Hypovitaminosis D in developing countries-prevalence, risk factors and outcomes. Nat Rev Endocrinol 6 : 550-561.

49. Tavera-Mendoza LE, White JH (2007) Cell defenses and the sunshine vitamin. Sci Am 297: 62-65, 68-70, 72

50. Mithal A, Wahl DA, Bonjour JP, Burckhardt P, Dawson-Hughes B, et al. (2009) Global vitamin D status and determinants of hypovitaminosis D. Osteoporos Int 20: 1807-1820

51. Peters BS, dos Santos LC, Fisberg M, Wood RJ, Martini LA (2009) Prevalence of vitamin D insufficiency in Brazilian adolescents. Ann Nutr Metab 54: 15-21.

52. Vahavihu K, Ala-Houhala M, Peric M, Karisola P, Kautiainen H, et al. (2010) Narrowband ultraviolet $B$ treatment improves vitamin $D$ balance and alters antimicrobial peptide expression in skin lesions of psoriasis and atopic dermatitis. Br J Dermatol 163: 321-328.

53. Peroni DG, Piacentini GL, Cametti E, Chinellato I, Boner AL (2011) Correlation between serum 25-hydroxyvitamin $\mathrm{D}$ levels and severity of atopic dermatitis in children. Br J Dermatol 164: 1078-1082.

54. Byremo G, Rod G, Carlsen KH (2006) Effect of climatic change in children with atopic eczema. Allergy 61:1403-1410

55. Taylor SC (2002) Skin of color: biology, structure, function, and implications for dermatologic disease. J Am Acad Dermatol 46: S41-S62.

56. Pathak MA (1999) Acute and chronic effects of the sun, In: Freedberg IM Wolff K, Goldsmith LA, SI K (eds.) Fitzpatrick's dermatology in general medicine, McGraw-Hill, New York, USA: 1598-1608.

57. Rigel EG, Lebwohl M, Rigel AC, Rigel DS (2003) Daily UVB exposure levels in high-school students measured with digital dosimeters. J Am Acad Dermatol 49:1112-1114.

58. Lamaud E, Schalla W (1984) Influence of UV irradiation on penetration of hydrocortisone. In vivo study in hairless rat skin. Br J Dermatol 27: 152-157.

59. Hong SP, Kim MJ, Jung MY, Jeon H, Goo J, et al. (2008) Biopositive effects of low-dose UVB on epidermis: coordinate upregulation of antimicrobial peptides and permeability barrier reinforcement. J Invest Dermatol 128: 28802887.

60. Jungersted JM, Hogh JK, Hellgren LI, Jemec GB, Agner T (2011) The impac of ultraviolet therapy on stratum corneum ceramides and barrier function. Photodermatol Photoimmunol Photomed 27: 331-333.

61. Schauber J, Dorschner RA, Yamasaki K, Brouha V, Gallo RL (2006) Control of the innate epithelial antimicrobial response is cell-type specific and dependent on relevant microenvironmental stimuli. Immunology 118: 509-519.

62. Samanek AJ, Croager EJ, Gies P, Milne E, Prince R, et al. (2006) Estimates of beneficial and harmful sun exposure times during the year for major Australian population centres. Med J Aust 184: 338-341.

63. Webb AR, Engelsen O (2006) Calculated ultraviolet exposure levels for a healthy vitamin D status. Photochem Photobiol 82: 1697-1703.

64. Amestejani M, Salehi BS, Vasigh M, Sobhkhiz A, Karami M, et al. (2012) Vitamin D supplementation in the treatment of atopic dermatitis: a clinical trial study. J Drugs Dermatol 11: 327-330. 